\title{
Heat shock proteins (HSP)-60, -70, -90, and 105 display variable spatial and temporal immunolocalization patterns in the involuting rat uterus
}

\author{
Narin Liman ${ }^{1}$ \\ Department of Histology and Embryology, Faculty of Veterinary Medicine, Erciyes University, Kayseri, Turkey.
}

\begin{abstract}
Uterine involution involves substantial tissue destruction and subsequent repair and remodelling, with similarities to the microenvironments present during wound healing. Although involution is a physiologically normal process, it may generate a stressful microenvironment for the uterine cells, and thus it can induce the expression of heat shock proteins (HSPs), which were originally identified as stress-responsive proteins. The aim of this study was to determine the spatial and temporal expression and localization of four heat shock proteins (HSPD1/HSP60, HSPA/HSP70, HSPC/HSP90 and HSPH1/HSP105/110) in the involuting rat uterus using immunohistochemistry. The HSPs were expressed in the luminal (LE) and glandular epithelium (GE), fibroblasts, mast cells, myometrial myocytes, perimetrial mesothelium and blood vessels, and each of the uterine tissues had distinctive patterns of HSP immunostaining. HSPD1/HSP60 was located in the cytoplasm, often with the granular appearance that is typical of organellar localization, whereas HSPA/HSP70, HSPC/HSP90 and HSPH1/HSP105 were located in the nucleus and cytoplasm. The immunolocalization patterns of all HSPs in the LE showed alterations that accompanied involution, but no difference was observed in the other uterine cells. HSPs were localized in the apical and basal cytoplasm of the LE on postpartum days 1,5 and 10 , but only in the apical cytoplasm on day 3. Furthermore, on day 3, HSPA/HSP70, HSPC/HSP90 and HSPH1/HSP105 immunostaining in the crypts and GE were stronger than those in the LE, whereas on day 10, the nuclear HSP90 immunoreaction was stronger in the LE than in the GE. These observations suggest that HSPs may be involved in many physiological processes, such as cell cycle control, cell proliferation, regulation of cell death and survival, and differentiation during the involution process.
\end{abstract}

Keywords: heat shock proteins, immunohistochemistry, uterine involution.

\section{Introduction}

The uterus is unique model for studying the cellular dynamics such as proliferation differentiation and apoptosis that occur in a temporal and cell-specific manner during the menstrual or oestrus cycle, pregnancy and postpartum involution. The uterine cellular dynamics are induced by the binding of ovarian hormones to oestrogen (ER) and progesterone receptors
(PR) and the subsequent regulation of transcription of the target genes in this tissue. Evidence shows that the function of the steroid hormone receptors is regulated by a group of constitutively synthesized heat shock proteins (HSPs) (Picard, 1998). HSPs, or stress proteins, are endogenous proteins that are either present constitutively, functioning as chaperones (Craig et al., 1994), or induced upon cell stress, such as heat, oxidative stress, ischaemia, and hypoxia (Knowlton et al., 1991). These proteins protect the cells from stressful stimuli by preventing the aggregation of unfolded proteins (Hendrick and Hartl, 1993) and may have critical functions during cell growth that are specifically associated with the cell cycle and the proliferative response (Milarski and Morimoto 1986; Galea-Lauri et al., 1996). They also regulate cellular apoptosis (Garrido et al., 2001; Parcellier et al., 2003) and immunogenicity (Garrido et al., 2001, Schmitt et al., 2007).

Mammalian HSPs were initially classified into different families according to their molecular weights (kilodaltons). However, the increasing number of members of HSP families in the last few years has made it necessary to revise the nomenclature. More recently, Kampinga et al., (2009) proposed a new nomenclature of human HSP families. This nomenclature is based on the systematic gene symbols that have been assigned by the HUGO Gene Nomenclature Committee (HGNC) and are used as the primary identifiers in databases such as Entrez Gene and Ensembl. According to this, human HSPs are classified into the following families: HSPH (HSP110), HSPC (HSP90), HSPA (HSP70), DNAJ (HSP40), HSPB (small HSP) and the chaperonin families HSPD/E (HSP60/HSP10) and CCT (TRiC) (Kampinga et al., 2009). However, the classic nomenclature is used in the most publications in mammals.

HSPD1/HSP60 is a chaperone that is primarly localized to the inner mitochondrial membrane and matrix, but in a variety of mammalian cells and tissues, 15 to $20 \%$ of cellular HSPD1/HSP60 is located in extramitochondrial sites, including the cytoplasmic face of the mitochondrial outer membrane, plasma membrane, Golgi compartments, endoplasmic reticulum, peroxisomes, cytoplasmic vesicles and granules (Soltys and Gupta 1996; 1997; Gupta and Knowlton 2002; Cappello et al., 2008).

The HSPA/HSP70 family of chaperones is currently known to be comprised of at least 13 highly related proteins that are constitutively expressed in the cytoplasm of mammalian cells under normal conditions to maintain protein structure homeostasis and are induced upon environmental stress (Nollen and 
Morimoto, 2002). For example, HSPA1A/HSP72, HSPA2/HSP70-2, HSPA6/HSP70B' and HSPA8/Hsc70 are primarily cytosolic, while HSPA9/Grp75/mortalin is associated with the mitochondria, and HSPA5/Grp78/BiP is located in the endoplasmic reticulum (ER) (Stetler et al., 2010). After the thermal stress, the cells overexpress and transport HSPA/HSP70 proteins into the nucleus. Nuclear HSPA/HSP70 is required for cell survival after stress damage (Song et al., 2015).

HSPC/HSP90 family contain both constitutive and inducible members, all of which are localized predominantly in various subcellular locations, including the cytosol, ER and mitochondria, but with different amounts in the nucleus. There are two major cytoplasmic isoforms of HSPC/HSP90, HSPC1/HSP90a $(84 \mathrm{kDa})$ and HSPC3/HSP90 $(86 \mathrm{kDa})$ (Sreedhar et al., 2004). HSPC $1 / \mathrm{HSP} 90 \alpha$ is known as the stressinduced, cytoprotective isoform (Sreedhar et al., 2004) and after exposure to heat stress, HSPC1/HSP90 $\alpha$ is more enriched in the nucleus (nuclear membrane) (Langer et al., 2003). Langer et al. (2003) suggested that HSPC1/HSP90 $\alpha$ nuclear staining was associated with the integrity of the nuclear envelope and the nuclear pore complexes. Cytoplasmic HSP90 $\alpha$ has also been shown to play a major role in growth promotion and cell cycle regulation (Milarski and Morimoto, 1986, Jerome et al., 1993). HSPC3/HSP90 $\beta$ typically has a more constitutive pattern of expression. Therefore, HSPC3/HSP90 $\beta$ is the major form of HSPC/HSP90 that is involved in normal cellular functions, such as maintenance of the cytoarchitecture, differentiation, and cytoprotection (Sreedhar et al., 2004).

The HSPH (HSP110/105) family are the first of the HSPs identified, but little has been known about the function of family members or structural biochemistry. The HSPH (HSP110/105) is composed of four members, namely HSPH1 (HSP105), HSPH2 (HSPA4; APG-2; HSP110), HSPH3 (HSPA4L; APG-1) and HSPH4 (HYOU1/Grp170; ORP150; HSP12A) (Kampinga et al., 2009). HSPH1/HSP105, which has two isoforms, alpha and beta, is localized to the cytoplasm and nucleus of mammalian cells under both nonstressed and stressed conditions (Yasuda et al., 1995; Saito et al., 2007; 2009). Saito et al. (2009) reported that HSPH1/HSP105 $\alpha$ is expressed constitutively in the cytoplasm of mammalian cells and can be further induced by heat shock and other stressors, whereas HSPH1/HSP105 $\beta$, an alternatively spliced form of HSPH1/HSP $105 \alpha$ specifically localized in the nucleus, is strictly heat-inducible. These authors also stated that HSPH family proteins, along with HSPA/HSP70, may play an important role in the protection of cells against deleterious stressors (Saito et al., 2009).

A growing body of evidence suggests that HSPs are produced and located in the mammalian reproductive tract, and they are involved in several processes essential for female reproduction. HSPs are implicated in the regulation of steroid function in the endometrium because HSPs bind to the ER and PR proteins and modulate their functions (Ramachandran et al., 1988; Pratt and Welsh, 1994; Tang et al., 1995; Koshiyama et al., 1995). HSPs demonstrate specific expression profiles in the uterus during the menstrual cycle of humans (Koshiyama et al., 1995; Tabibzadeh et al., 1996; Komatsu et al., 1997; Tabibzadeh and Broome, 1999; Neuer et al., 2000; Lachance et al., 2007) and in the oestrous cycle of animal species, such as rats (Ciocca et al., 1996; Yuan et al., 2009), mice (Ramachandran et al., 1988; Papaconstantinou et al., 2003), and pigs (Gu et al., 2012). In the early stages of pregnancy, these proteins are expressed in both the embryo and maternal decidua (Grigore and Indrei, 2001). During the first trimester of pregnancy, HSPs can also be detected in the decidua, and they are detected in placental tissues throughout pregnancy (Neuer et al., 1996; Shah et al., 1998; Zigert et al., 1999; Sotiriou et al., 2004). These studies reveal the important roles of HSPs in various biological responses in the uterus during the menstrual or sexual cycle and pregnancy, including those related to the steroid hormones and steroid hormone receptors. However, there are no published reports on the expression and cellular/subcellular localization of HSPs in the uterus during the postpartum involution period in humans and animals, due to the practical and ethical issues of collecting appropriate tissue samples. Therefore, the role of HSPs in postpartum uterine remodelling still remains enigmatic and animal models are necessary to decipher both the molecular and mechanical events associated with uterine involution. Rats have long been used as models of mammalian reproduction. The short oestrous cycle and gestation period and rapid uterine involution period within 5-6 days postpartum make the rat a suitable animal model for research on all aspects of reproductive biology. The involuting rat uterus is also useful for assessments of the regeneration and repair processes of the reproductive tract because epithelial regeneration occurs within 36 hours after parturition and the first postpartum ovulation occurs approximately 18 hours after parturition (reviewed in Hamid and Zakaria, 2013). Postpartum uterine involution involves substantial tissue destruction and subsequent repair and remodelling. Therefore, this process has features in common with tissue injury and repair in other tissues (Salamonsen, 2003). Recent studies (Atalay et al., 2009) have shown that HSPs play important roles in normal skin wound healing by modulating inflammation, cell proliferation, migration and collagen synthesis. Based on this evidence, it is tempting to hypothesize that the uterine involution conditions may generate a stressful environment for the uterine cells involved in the regeneration process and induce the expression of HSPs, which were originally identified as stress-responsive proteins. To clarify these issues, the present study investigated, by the immunohistochemistry, the spatial and temporal expression and localization patterns of four heat shock proteins (HSPD1/HSP60, HSPA/HSP70, HSPC/HSP90 and HSPH1/HSP105) in the involuting rat uterus.

\section{Materials and methods}

\section{Animals and tissue preparation}

Female Wistar rats, 8-10 weeks old were 
purchased from the Hakan Çetinsaya Experimental and Clinical Research Center of Erciyes University, housed individually under standard environmental conditions (12L:12D cycle), and provided standard rat chow and water ad libitum.

The stages of the oestrous cycle were determined by examinations of vaginal smears. Female rats in oestrous were mated with males, and the day on which spermatozoa were observed in the morning vaginal smear was designated day 1 of pregnancy. A total of 20 timed-pregnant female rats were housed individually and observed daily for delivery. Twenty of the 20 animals in this study completed delivery of all pups on day 22 or day 23 of pregnancy. The day on which the pups were delivered was designated as day 1 postpartum (PP). After birth, the pups were housed with their dam during the entire experimental period and were allowed to suckle their dam. All pups were removed from their dams on the morning of each experiment. On days 1, 3, 5 and 10 postpartum (five rats per group), the animals were anesthetized with a mixture of ketamine hydrochloride and xylazine $(80 \mathrm{mg} / \mathrm{kg}$ and $10 \mathrm{mg} / \mathrm{kg}$, respectively, i.p.) and then sacrificed by cervical dislocation. Next, a longitudinal median incision was made in the abdomen, and the uterine horns were removed, immediately fixed in $10 \%$ formalin-alcoholic solution for $18 \mathrm{~h}$, and processed for routine paraffin histology.

This study was approved by the Department of Experimental Animals Ethic Committee, University of Erciyes (approval number 10/27). During all experiments, efforts were made to minimize both animal suffering and the number of rats used.

\section{Immunohistochemistry (IHC)}

Histological and immunohistochemical analysis were performed on $5 \mu \mathrm{m}$ thick tissue sections (three sections per slide) placed on charged poly-L-lysinecoated glass slides. The histological characteristics of the involuting uterus on each postpartum day were established by standard light microscopic evaluations of sections stained with modified Mallory's triple stain (Crossmon, 1937) in each postpartum day.

IHC was performed using a streptavidin-biotinperoxidase technique, as previously described (Liman et al., 2013). In brief, the uterine sections were deparaffinized in xylene and rehydrated through a graded ethanol series $(100,100,95,80$ and $70 \%)$ for 3 min each. Endogenous peroxidase was quenched with $3 \%$ hydrogen peroxide in methanol, and the antigens were retrieved by boiling in $10 \mathrm{mM}$ citrate buffer $(\mathrm{pH}$ 6.0). Nonspecific binding was blocked with a blocking solution (Ultra V Block ${ }^{\circledR}$, Thermo Fisher Scientific, LabVision Corporation, Fremont, CA, USA) for $5 \mathrm{~min}$ at room temperature. Next, the slides were incubated with the primary antibodies (Table 1 ) overnight at $4^{\circ} \mathrm{C}$ in a humid chamber. Then, the slides were washed in
PBS, incubated with biotinylated anti-rabbit antiserum (Thermo Fisher Scientific Lab Vision, Fremont, USA) or biotinylated anti-goat antiserum (VECTASTAIN $\AA$ Elite ABC-Peroxidase Kits (Goat) PK-6105) for $30 \mathrm{~min}$, and washed in PBS. The sections were incubated with streptavidin peroxidase for $20 \mathrm{~min}$ or $30 \mathrm{~min}$ at room temperature and then washed with PBS. The bound antibodies were visualized using 3,3' diaminobenzidine tetrahydrochloride (DAB) as a chromogen (Thermo Fisher Scientific Lab Vision Corporation, Fremont, USA). Finally, the sections were counterstained with Gill's haematoxylin, dehydrated through an alcohol series, cleared in xylene, and mounted in Entellan with a cover slip.

\section{Controls for Immunohistochemistry}

The specificity of these antibodies has been tested by the suppliers. Furthermore, the specificity of the immunohistochemical procedures was checked using negative and positive controls. According to the manufacturer's recommendations, the sections obtained from archival blocks of human colon and breast carcinoma were incubated with primary antibodies as the positive controls. Negative control sections were incubated with nonimmune rabbit IgG (sc-2027, Santa Cruz Biotechnology, Santa Cruz, CA) or goat IgG (sc2028, Santa Cruz Biotechnology, Santa Cruz, CA) instead of primary antibodies. All of the samples were treated according to the same protocol. Furthermore, for each protein, the samples from different postpartum periods were stained at the same time.

\section{Quantification of immunoexpression}

The uterine sections were assessed using an Olympus BX-51 microscope equipped with a digital camera (Olympus dp72; Olympus, Tokyo, Japan). Three different transverse sections of the uterine horn from each animal were first examined at low magnification $(\times 10)$ to individually judge (NL) the quality of immunostaining, the cell labelling pattern, and potential histomorphological changes throughout postpartum period. Because HSP IHC scoring algorithms have not been optimized and standardized, in this study, the immunohistochemical staining was semiquantitatively evaluated using a score (intensity score, IS) based on the intensity of the nuclear and cytoplasmic staining (-, negative reactivity; + , weak staining; ++ , moderate staining and +++, strong staining) (Detre et al., 1995; Li et al., 2014; Alan et al., 2015). The cytoplasmic and nuclear staining was separately scored in four different layers (the luminal epithelium, glandular epithelium and endometrial stroma and myometrial smooth muscle cells) of the uterus. The immunostaining of the blood vessels in the endometrium was described without scoring. 
Table 1. The antibodies used for immunohistochemical analysis (IHC)

\begin{tabular}{|c|c|c|c|c|c|}
\hline Antibody & Host & Immunogen & Supplier/Catalog number & Dilution & Reactivity \\
\hline \multicolumn{6}{|l|}{ Primary antibodies } \\
\hline HSP60 (N-20) polyclonal & Goat & $\begin{array}{l}\text { A peptide mapping at the N-terminus of HSP } 60 \text { of } \\
\text { human origin }\end{array}$ & Santa Cruz Biotechnology Inc./sc-1052 & $1: 125$ & $\begin{array}{l}\text { human, rat, mouse, } \\
\text { equine, canine, pig, } \\
\text { bovine, avian }\end{array}$ \\
\hline HSP70 (K-20) polyclonal & Goat & $\begin{array}{l}\text { A peptide mapping at the C-terminus of HSP70 of } \\
\text { human origin. This antibody identifies epitopes on } \\
\text { inducible HSP70. }\end{array}$ & Santa Cruz Biotechnology Inc./sc-1060 & $1: 100$ & $\begin{array}{l}\text { human, rat, mouse, } \\
\text { equine, canine, pig, } \\
\text { bovine }\end{array}$ \\
\hline HSP90 $\alpha / \beta(N-17)$ polyclona & Goat & $\begin{array}{l}\text { A peptide mapping at the N-terminus of HSP90 } \alpha \text { of } \\
\text { human origin }\end{array}$ & Santa Cruz Biotechnology Inc./sc-1055 & $1: 100$ & $\begin{array}{l}\text { human, rat, mouse, } \\
\text { equine, canine, pig, } \\
\text { bovine, avian }\end{array}$ \\
\hline HSP105 (N-187) polyclonal & Rabbit & $\begin{array}{l}\text { amino acids } 187-512 \text { centrally located within the } 858 \\
\text { residue of HSP } 105 \text { of mouse origin. This antibody } \\
\text { detects HSPH1/HSP105 and, to a lesser extent, } \\
\text { HSPH2 (HSPA4; APG-2; HSP110), HSPH3 } \\
\text { (HSPA4L; APG-1). }\end{array}$ & Santa Cruz Biotechnology Inc./sc-6241 & $1: 100$ & $\begin{array}{l}\text { human, rat, mouse, } \\
\text { equine, canine, pig }\end{array}$ \\
\hline \multicolumn{6}{|l|}{ Secondary antibodies } \\
\hline Anti-goat IgG (biotinylated) Rabbit & Rabbit & & $\begin{array}{lll}\text { VECTASTAIN }{ }^{\circ} & \text { Elite } & \text { ABC- } \\
\text { Peroxidase Kits (Goat) } & \text { PK-6105 }\end{array}$ & & \\
\hline Anti-rabbit IgG (biotinylated)Goat & Goat & & $\begin{array}{l}\text { Ultravision Detection Sytem/HRP } \\
\text { Thermo Fisher Scientific Lab Vision, } \\
\text { TR-125-HL }\end{array}$ & & \\
\hline
\end{tabular}




\section{Results}

As expected, human colon, breast carcinoma and placenta samples showed positive reactivity for all HSPs (Fig. 1), whereas negative controls, which were performed for each antibody, showed no specific staining (Figs. 2-5).The cellular localization and immunostaining scores of HSPs within the uterine tissues are summarized in Table 2. The expression levels of four heat shock proteins (HSPD1/HSP60, HSPA/HSP70, HSPC/HSP90 and HSPH1/HSP105) were detected in the endometrial luminal and glandular epithelia, endometrial fibroblasts, macrophages, mast cells and myometrial myocytes, vascular endothelium and smooth muscle cells throughout the postpartum period. Each of the uterine tissues had distinctive patterns of HSP immunostaining and each of HSP exhibited different subcellular localization (Table 2 and Figs. 2-6).

On all postpartum days, HSPD1/HSP60 immunostaining was localized to the cell cytoplasm and was characterized by a punctate-granular pattern, whereas specific immunoreactivities for HSPA/HSP70, HSPC/HSP90 and HSPH1/HSP105 were observed in the nucleus (in the nuclear membrane) and cytoplasm of uterine cells.
The immunolocalization of HSPD1/HSP60 in the rat uterus during postpartum involution

\section{Uterine luminal and glandular epithelium}

The HSP60 immunostaining pattern in the luminal and crypt epithelia of the endometrium was changed in response to structural changes in the epithelial cells during the postpartum involution process. On postpartum day 1, punctate-granular immunostaining for the HSPD1/HSP60 protein was observed in the apical and basal cell cytoplasm and near the nuclear membrane of the luminal and crypt epithelium. On postpartum day 3, HSPD1/HSP60 immunostaining was detected in the apical and basal cytoplasm of crypt epithelium; however, due to the decreased cellular height, HSPD1/HSP60 immunostaining was only observed in the apical cytoplasm of the luminal epithelium. On postpartum day 5 and thereafter, coarsely punctate granular HSPD1/HSP60 immunostaining was localized to the apical and basal cytoplasm of the luminal and glandular epithelia. In addition, HSPD1/HSP60 immunostaining was also detected in the intraepithelial lymphocytes (Fig. 2)

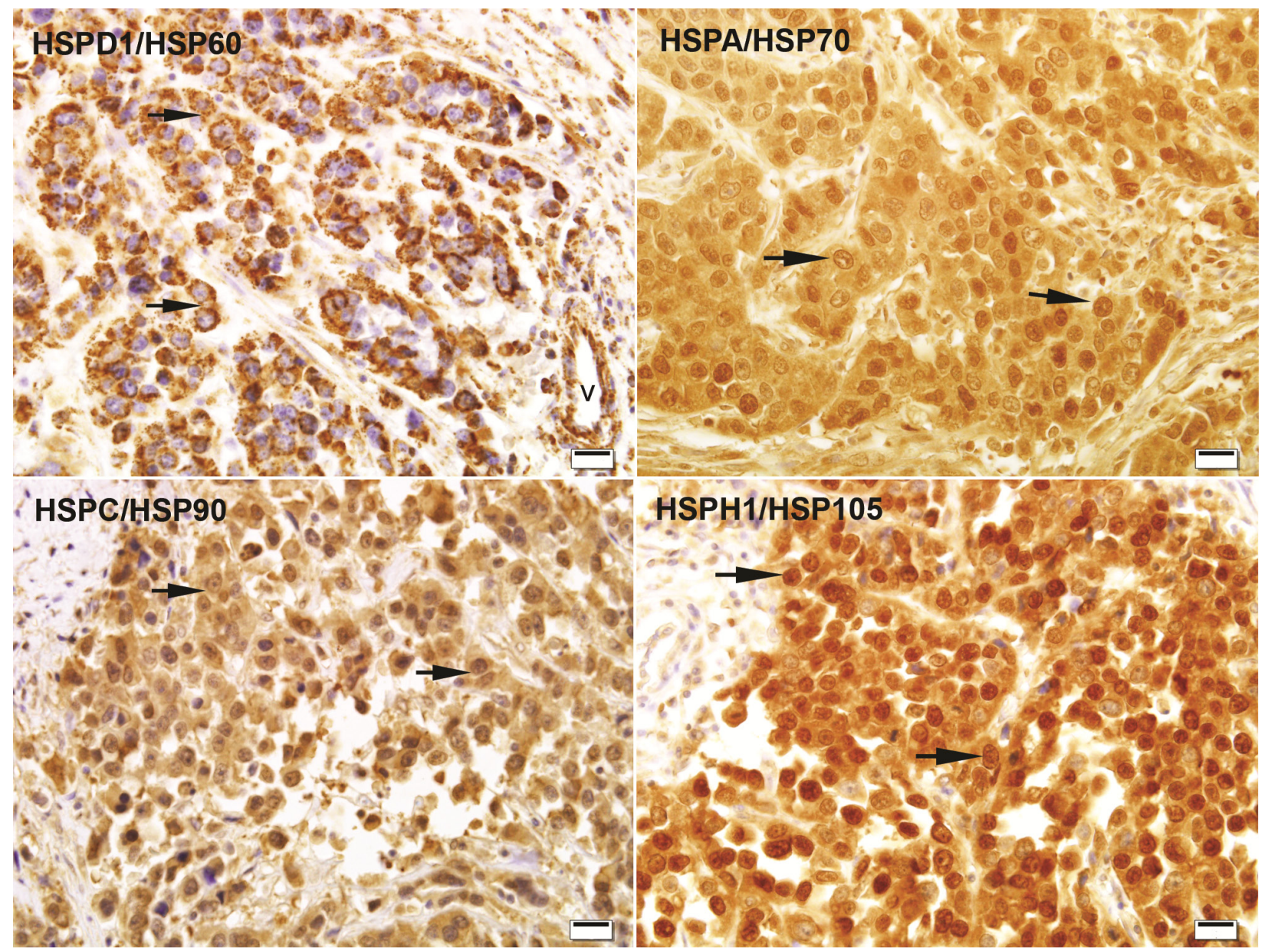

Figure 1. Colon carcinoma tissue section as positive control for HSPD1/HSP60, HSPA/HSP70, HSPC/HSP90 and HSPH1/HSP105. HSPD1/HSP60 immunostaining was localized to the cell cytoplasm and characterized by a punctate-granular pattern (arrows), whereas specific immunoreactivities for HSPA/HSP70, HSPC/HSP90 and HSPH1/HSP105 were observed in the nucleus and cytoplasm of carcinoma cells (arrows). Scale bars $=20 \mu \mathrm{m}$. 


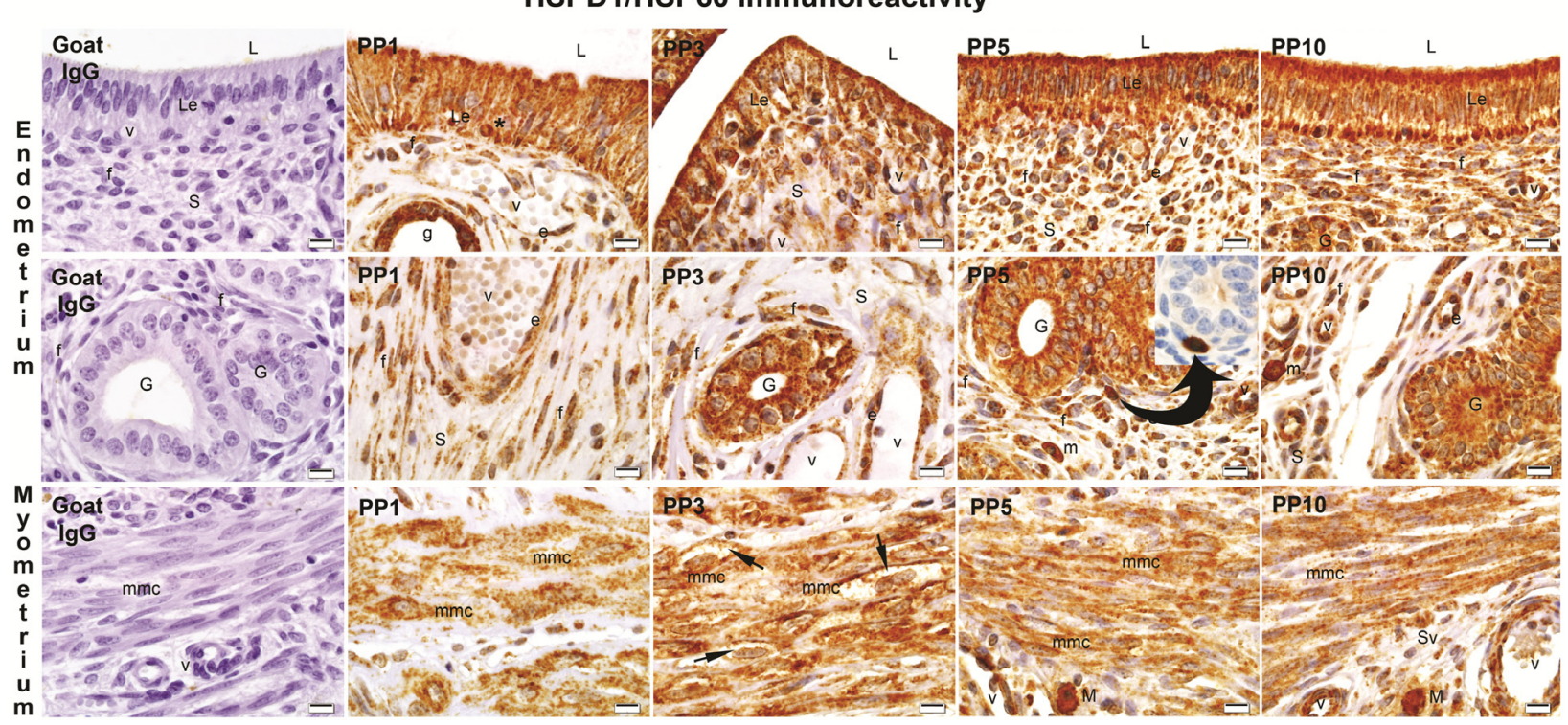

Figure 2. Representative samples showing expression of HSPD1/HSP60 in rat endometrium and myometrium of day 1 postpartum (PP1), day 3 postpartum (PP3), day 5 postpartum (PP5), day 10 postpartum (PP10), and negative controls. Nonimmune goat IgG was used a negative control. HSP60 immunostaining was localized in the cytoplasm, often with a granular appearance, of uterine cells. On postpartum day 3 , an unstained clear space was found next to the nucleus in the cytoplasm of myometrial myocytes (arrow head) Ce: crypt epithelim, e: endothelial cells, f: fibroblasts, G: endometrial gland, ismc: inner myometrial smooth muscle cells, L: lumen, Le: luminal epithelium, m: macrophage, M: mast cells, mmc: myometrial smooth muscle cells, S: stroma, Sv: Stratum vasculare, v: blood vessel, black arrows: HSP60-negative region in the cytoplasm of myometrial smooth muscle cells, white arrows: lymphocytes, star: intraepithelial lymphocytes. Scale bars $=10 \mu \mathrm{m}$.

Table 2. Scoring for specific immunostaining of HSPD1/HSP60, HSPA/HSP70, HSPC/HSP90 and HSPH1/HSP105 in the rat uterus during the postpartum involution period.

\begin{tabular}{|c|c|c|c|c|c|}
\hline Postpartum days & Luminal & Crypt & Glandular & Endometrial & Myometrial \\
\hline PP/HSPs & Epithelium & Epithelium & Epithelium & Fibroblasts & Muscle cells \\
\hline \multicolumn{6}{|l|}{ HSPD1/HSP60 } \\
\hline PP1 & $\mathrm{gc} / \mathrm{ac}, \mathrm{bc},+++$ & gc/ac, bc, +++ & $\mathrm{gc} /+++$ & $\mathrm{gc} /++$ & $\mathrm{gc} /+++$ \\
\hline PP3 & gc/ac, ++ & $\mathrm{gc} / \mathrm{ac}, \mathrm{bc}+++$ & gc/ac, bc, +++ & $\mathrm{gc} /++$ & $\mathrm{gc} /+++$ \\
\hline PP5 & gc/ac, bc +++ & $\mathrm{gc} / \mathrm{ac}, \mathrm{bc}+++$ & gc/ac, bc, +++ & $\mathrm{gc} /+++$ & $\mathrm{gc} /+++$ \\
\hline PP10 & $\mathrm{gc} / \mathrm{ac}, \mathrm{bc}+++$ & & gc/ac, bc, +++ & $\mathrm{gc} /+++$ & $\mathrm{gc} /+++$ \\
\hline \multicolumn{6}{|l|}{ HSPA/HSP70 } \\
\hline PP1 & $\mathrm{c} /+++, \mathrm{n} /++$ & $\mathrm{c} /+++, \mathrm{n} /++$ & $\mathrm{c} /+++, \mathrm{n} /++$ & $\mathrm{c}, \mathrm{n} /+++$ & $\mathrm{c} /+++, \mathrm{n} /++$ \\
\hline PP3 & $\mathrm{c} / \mathrm{ac},+++, \mathrm{n} /+++$ & $\mathrm{c} /+++, \mathrm{n} /++$ & $\mathrm{c} /+++, \mathrm{n} /++$ & $\mathrm{c}, \mathrm{n} /+++$ & $\mathrm{c} /++, \mathrm{n} /++$ \\
\hline PP5 & $\mathrm{c} /+++, \mathrm{n} /+++$ & $\mathrm{c} /+++, \mathrm{n} /++$ & $\mathrm{c} /+++, \mathrm{n} /++$ & $c, n /+++$ & $\mathrm{gc} /+++$ \\
\hline PP10 & $\mathrm{c} /+++, \mathrm{n} /+++$ & & $\mathrm{c} /++, \mathrm{n} /++$ & $\mathrm{c}, \mathrm{n} /+++$ & $\mathrm{gc} /+++$ \\
\hline \multicolumn{6}{|l|}{ HSPC/HSP90 } \\
\hline PP1 & $\mathrm{c} /++, \mathrm{n} /+++$ & $\mathrm{c} /++, \mathrm{n} /++$ & $\mathrm{c} /+++, \mathrm{n} /+++$ & $\mathrm{c} /++, \mathrm{n} /+++$ & $\mathrm{c} /++, \mathrm{n} /++$ \\
\hline PP3 & $\mathrm{c} / \mathrm{ac},++, \mathrm{n} /+++$ & $\mathrm{c} /++, \mathrm{n} /++$ & $\mathrm{c} /++, \mathrm{n} /++$ & $\mathrm{c} /++, \mathrm{n} /+++$ & $\mathrm{c} /+, \mathrm{n} /++$ \\
\hline PP5 & $\mathrm{c} /++, \mathrm{n} /+++$ & $\mathrm{c} /++, \mathrm{n} /++$ & $\mathrm{c} /++, \mathrm{n} /++$ & $\mathrm{c} /++, \mathrm{n} /+++$ & $\mathrm{c} /++, \mathrm{n} /++$ \\
\hline PP10 & $\mathrm{c} /++, \mathrm{nh} /+++$ & $\mathrm{c} /++, \mathrm{n} /++$ & $\mathrm{c} /++, \mathrm{n} /++$ & $\mathrm{c} /++, \mathrm{n} /+++$ & $\mathrm{c} /++, \mathrm{n} /++$ \\
\hline \multicolumn{6}{|l|}{ HSPH1/HSP105 } \\
\hline PP1 & $\mathrm{c} /+++, \mathrm{n} /+++$ & $\mathrm{c} /+++, \mathrm{n} /++$ & $\mathrm{c} /+++, \mathrm{n} /+++$ & $\mathrm{c} /+++, \mathrm{n} /+++$ & $\mathrm{c} /++, \mathrm{n} /+$ \\
\hline PP3 & $\mathrm{c} / \mathrm{ac},+++, \mathrm{n} /+++$ & $\mathrm{c} /+++, \mathrm{n} /++$ & $\mathrm{c} /+++, \mathrm{n} /+++$ & $\mathrm{c} /+++, \mathrm{n} /+++$ & $\mathrm{c} /++, \mathrm{n} /+$ \\
\hline PP5 & $\mathrm{c} /+++, \mathrm{n} /+++$ & $\mathrm{c} /+++, \mathrm{n} /++$ & $\mathrm{c} /+++, \mathrm{n} /+++$ & $\mathrm{c} /+++, \mathrm{n} /+++$ & $\mathrm{c} /+++, \mathrm{n} /+$ \\
\hline PP10 & $\mathrm{c} / \mathrm{lm},+++, \mathrm{n} /+++$ & & $\mathrm{c} /+++, \mathrm{n} /+++$ & $\mathrm{c} /+++, \mathrm{n} /+++$ & $\mathrm{c} /+++, \mathrm{n} /+$ \\
\hline
\end{tabular}

Staining intensity: -, negative (no staining even at high magnification), + , weak (only visible at high magnification), ++ , moderate (readily visible at low magnification), +++, strong (strikingly positive at low power magnification) staining. Subcellular localization of staining: c, cytoplasmic staining; n, nuclear membrane staining; nh, homogeneous nuclear staining; ac, apical cytoplasmic staining; bc, basal cytoplasmic staining; gc, punctate-granular cytoplasmic staining; $1 \mathrm{~m}$, lateral membrane staining. 


\section{Uterine stroma}

As the number of stromal cells, including endometrial fibroblasts and macrophages, within the uterine stroma on the first day of involution was reduced compared with the other postpartum days, the number of fibroblasts exhibiting positive immunoreactivity for HSPD1/HSP60 was also low (Fig. 2 ). Between postpartum days 3 and 10, a dramatic increase in the number of fibroblasts showing positive immunoreactions for HSPD1/HSP60 was observed due to the concomitant decrease wall thickness of the stroma and the increase of fibroblast density. Beginning on day 5 after delivery, the HSPD1/HSP60-positive signal was also localized to one or two large granules immediately adjacent to the cell nucleus. On postpartum day 10 , the number of HSPD1/HSP60 positive fibroblasts in the subepithelial stroma was increased compared with the deep stroma. During the entire postpartum involution period, the macrophages presented moderate granular cytoplasmic staining for HSPD1/HSP60. Furthermore, the mast cells present in the connective tissue surrounding the blood vessels in the deep endometrial stroma and the stratum vasculare of the myometrium showed strong cytoplasmic immunostaining for HSPD1/HSP60 (Fig. 6). However, the immunolocalization pattern and immunostaining intensity of HSPD1/HSP60 in the fibroblasts, macrophages and mast cells did not change from day 1 to day 10, regardless of the postpartum day. The endothelium and smooth muscle cells of blood vessels in the uterine stroma exhibited positive immunoreactivity for HSPD1/HSP60 (Figs. 2 and 6).

\section{Myometrium}

Following day 3 after parturition, it was determined that the thickness of myometrium decreased with the advancement of postpartum days and reached a minimum on postpartum day 10 , reflecting a reduction in the size of individual cells in the myometrium. On postpartum day 3, a large unstained region was observed next to the nucleus in the cytoplasm of myocytes by immunohistochemistry. On all of the postpartum days investigated, the myocytes of the inner and outer myometrium displayed strong immunoreaction for HSPD1/HSP60. The intensity of HSPD1/HSP60 immunostaining in the myometrium were not influenced by postpartum involution day (Fig. 2).

The immunolocalization of HSPA/HSP70 in the rat uterus during postpartum involution

\section{Uterine luminal and glandular epithelium}

The pattern of HSPA/HSP70 immunostaining in the luminal epithelium showed alterations that accompanied involution. On postpartum day 1, the nuclear immunolabelling for HSPA/HSP70 was localized to the nuclear membrane and the cytoplasmic immunostaining was observed throughout the cells of the luminal and crypt epithelium. On postpartum day 3 , the intense cytoplasmic signal of HSPA/HSP70 was mainly localized to the crypt and glandular epithelium, whereas, weak cytoplasmic HSPA/HSP70 immunostaining was observed in the luminal epithelium. However, the nuclear HSPA/HSP70 immunostaining intensity was similar in the luminal, crypt and glandular epithelia. On postpartum day 5 and thereafter, the HSPA/HSP70 immunolabelling in the luminal epithelium was similar to that observed in the glandular epithelium (Fig. 3).

\section{Uterine stroma}

During the entire postpartum involution period, whereas endometrial fibroblasts exhibited with a strong cytoplasmic and nuclear staining (Fig. 3), the macrophages (Fig. 3) and mast cells (Fig. 6) produced a strong cytoplasmic staining for HSPA/HSP70. However, whereas the amount of HSPA/HSP70immunopositive fibroblasts and macrophages increased with the advance of postpartum days and reached a maximum on postpartum day 10 , the immunostaining intensity remained relatively stable throughout the postpartum period. Blood vessels exhibited a strong HSPA/HSP70 expression in endothelial and smooth muscle cells (Figs. 3 and 6).

\section{Myometrium}

In the myometrium, the cytoplasmic and nuclear immunoreactivity for HSPA/HSP70 was of a strong intensity on day 1 of the postpartum period, and moderate on postpartum days 3, 5 and 10 (Fig. 3).

The immunolocalization of HSPC/HSP90 in the rat uterus during postpartum involution

\section{Uterine luminal and glandular epithelium}

The HSPC/HSP90 immunoreactivity in the endometrial epithelium exhibited different subcellular localization patterns in a time-dependent manner (Fig. 4). The nuclear immunostaining for HSPC/HSP90 was more intense than the cytoplasmic staining in all cells. On postpartum day 1 , the entire luminal epithelium produced moderate cytoplasmic immunostaining for HSPC/HSP90, whereas the nuclear immunostaining was localized to the nuclear membrane and was negative in some cells of the epithelium. During this period, the HSPC/HSP90 immunostaining in the endometrial glands with wide lumen was more intense than in the luminal epithelium and crypts. On postpartum day 3 , although the luminal epithelium presented weak cytoplasmic and moderate nuclear HSPC/HSP90 immunoreactivity, the crypt and glandular epithelia exhibited moderate cytoplasmic and nuclear staining. On postpartum day 5, the intensity of HSPC/HSP90 cytoplasmic staining in the luminal epithelium was similar to that observed in the glandular epithelium. However, on postpartum day 10, the nuclear immunostaining intensity for HSPC/HSP90 always appeared to be distinctly stronger in the luminal 
epithelium than in the glandular epithelium and other cellular components of the uteri. Furthermore, the nuclear staining in the luminal epithelium was the typical "homogeneous" pattern of nuclear staining and was stronger on postpartum day 10 compared with the other days (Fig. 4).

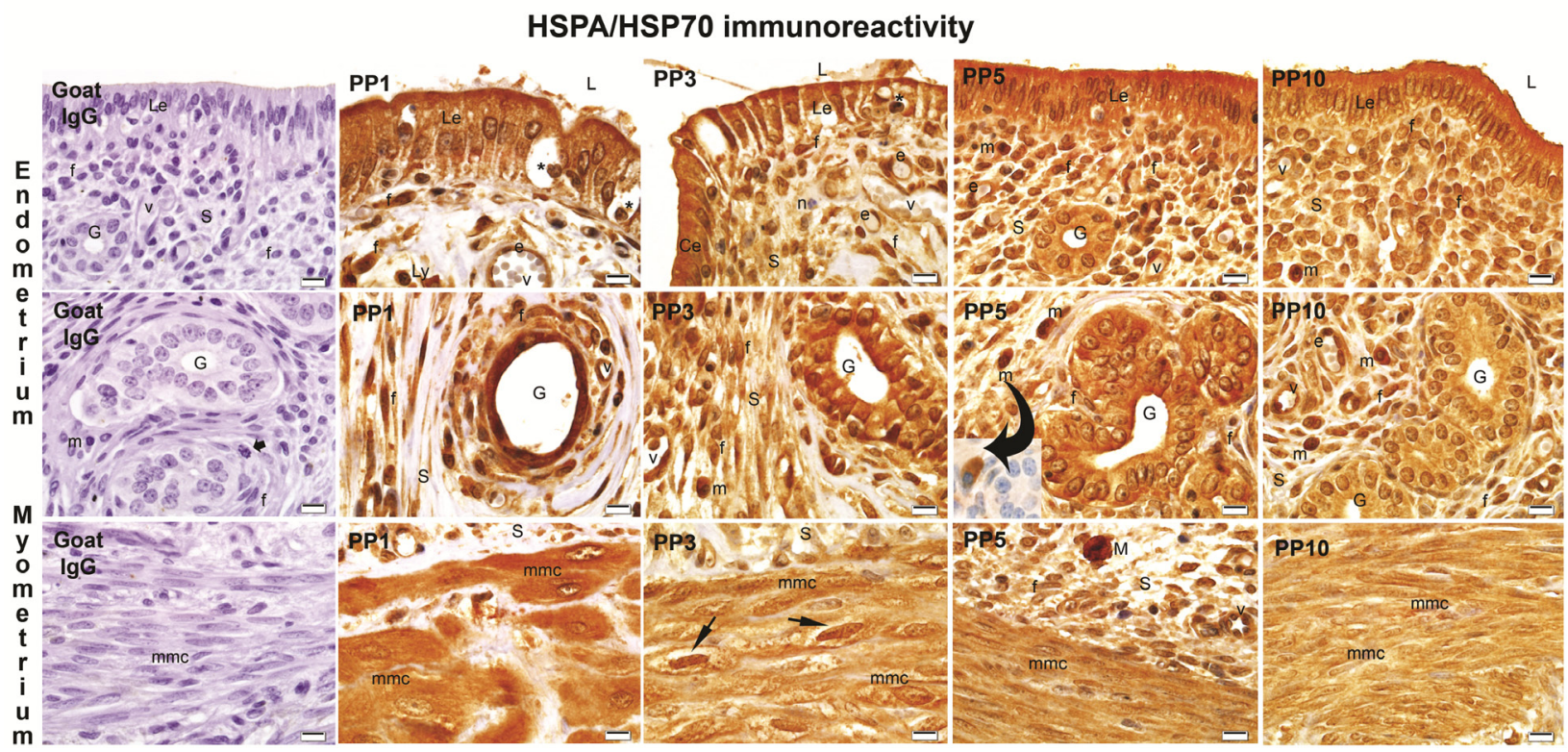

Figure 3. Representative samples showing expressin of HSPA/HSP70 in rat endometrium and myometrium of day 1 postpartum (PP1), day 3 postpartum (PP3), day 5 postpartum (PP5), day 10 postpartum (PP10), and negative controls. Nonimmune goat IgG was used a negative control. Nuclear and cytoplasmic immunostaining for HSPA/HSP70 were detected in the luminal (Le) and glandular (G) epithelial cells, stromal fibroblast (f) and macrophages $(\mathrm{m})$ of the endometrium and in the smoth muscle cells $(\mathrm{mmc})$ of myometrium. On postpartum day 3 , a large unstained region was observed next to the nucleus in the cytoplasm of myometrial myocytes (arrow head). The mast cells (m) and endothelium (e) and smooth muscle cells of blood vessels (v) exhibited strong immunoreactivity for HSPA/HSP70. Ce: crypt epithelim, e: endothelial cells, G: endometrial gland, ismc: inner myometrial smooth muscle cells, L: lumen, Le: luminal epithelium, m: mast cells, osmc: outer myometrial smooth muscle cells, smc: myometrial smooth muscle cells; S: stroma, Sv: Stratum vasculare, v: blood vessel, black arrow heads: macrophages, black arrows: fibroblasts, thin black arrows: HSP70-negative region in the cytoplasm of myometrial smooth muscle cells, white arrows: lymphocytes, white arrow heads: siderophages, stars: intraepithelial lymphocytes. Scale bars $=10 \mu \mathrm{m}$.

\section{Uterine stroma}

In the endometrial stroma, the fibroblasts presented with moderate cytoplasmic and strong nuclear HSPC/HSP90 immunoreactivity, whereas macrophages (Fig. 4) and mast cells located around the blood vessels in the deep endometrial stroma and the stratum vasculare of the myometrium (Fig. 6) produced a strong cytoplasmic reaction throughout the postpartum involution period. Blood vessels exhibited a moderate cytoplasmic and strong nuclear HSPC/HSP90 expression in endothelial and smooth muscle cells (Figs. 4 and 6).

\section{Myometrium}

In the myometrium, the HSPC/HSP90 immunoreactivity was moderately positive in the nucleus and cytoplasm of myocytes. This immunoreaction did not alter from days 1 to 10 of the involution (Fig. 4).

The immunolocalization of HSPH1/HSP105 in the endometrial epithelium during postpartum involution

\section{Uterine luminal and glandular epithelium}

During day 1 of the postpartum involution period, the entire luminal epithelium produced positive cytoplasmic and nuclear HSPH1/HSP105 staining, whereas negative cytoplasmic staining was observed in some cells of the epithelium on day 3 of the postpartum period. On postpartum days 5 and 10 , this immunoreaction was observed in the nuclei and cytoplasm of the luminal epithelial cells and was intensified in the lateral membrane and reached a strong intensity. However, the immunoreactivity for HSPH1/HSP105 in the glandular epithelium did not vary during the postpartum period (Fig. 5). 


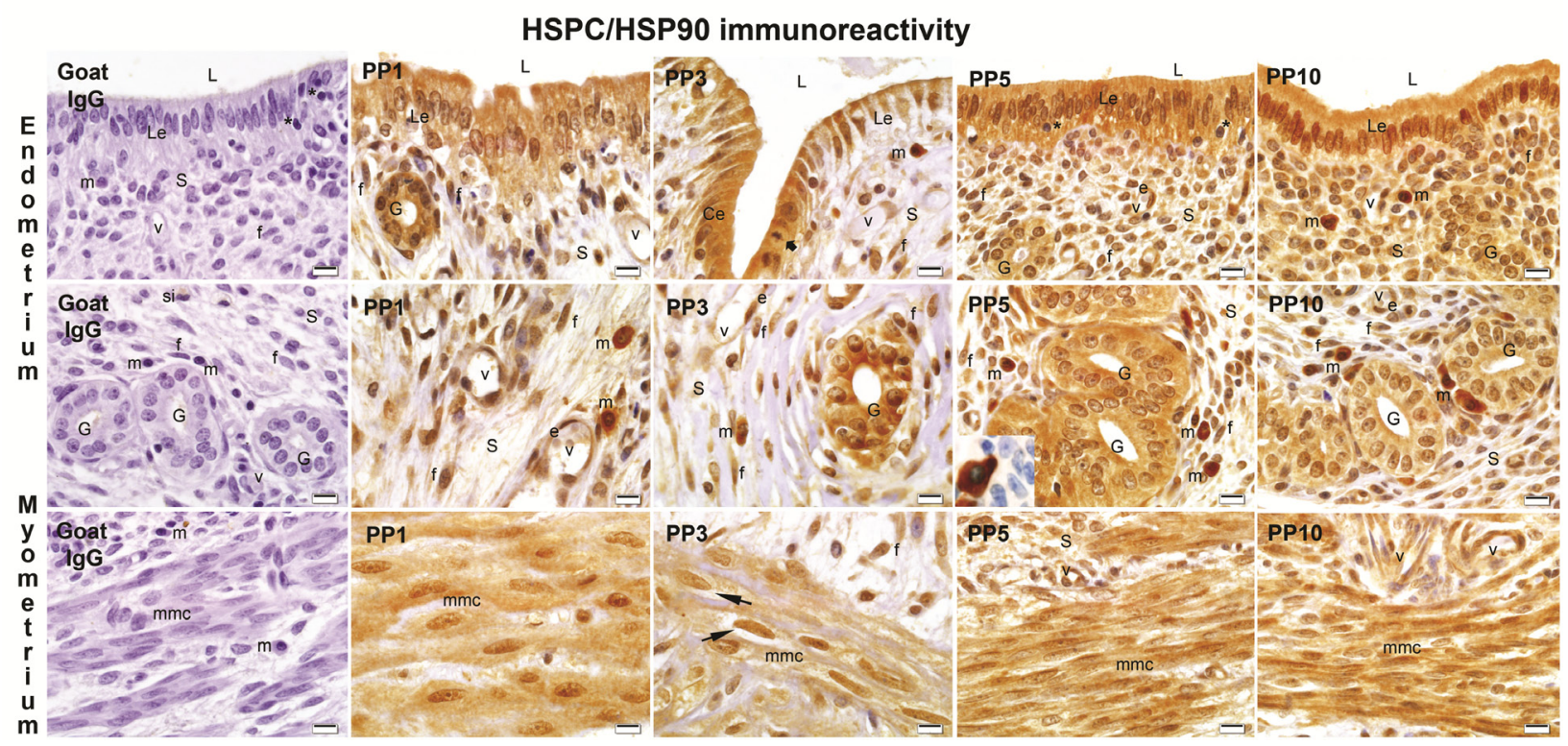

Figure 4. Representative samples showing expression of HSPC/HSP90 in rat endometrium and myometrium of day 1 postpartum (PP1), day 3 postpartum (PP3), day 5 postpartum (PP5), day 10 postpartum (PP10), and negative controls. Nonimmune goat IgG was used a negative control. Nuclear and cytoplasmic immunostaining for HSPC/HSP90 were observed in the luminal (Le) and glandular (G) epithelialium, stromal fibroblast (f) and macrophages $(\mathrm{m})$ of endometrium and in the myometrial myocytes $(\mathrm{mmc})$. On postpartum day 3 , a large unstained region was observed next to the nucleus in the cytoplasm of myometrial myocytes (arrow head). On postpartum day 10, the intensity of nuclear HSPC/HSP90 immunostaining in the luminal epithelium was stronger than in the glandular epithelium and other cellular components of the uteri. Ce: crypt epithelim, e: endothelial cells, G: endometrial gland, ismc: inner myometrial smooth muscle cells, L: lumen, Le: luminal epithelium, m: mast cells, osmc: outer myometrial smooth muscle cells, smc: myometrial smooth muscle cells; S: stroma, Sv: Stratum vasculare, v: blood vessel, black arrow heads: macrophages, black arrows: fibroblasts, thin black arrows: HSP90negative region in the cytoplasm of myometrial smooth muscle cells. Scale bars $=10 \mu \mathrm{m}$.



Figure 5. Representative samples showing expression of HSPH1/HSP105 immunoreactivity in rat endometrium and myometrium of day 1 postpartum (PP1), day 3 postpartum (PP3), day 5 postpartum (PP5), day 10 postpartum (PP10), and negative controls. Nonimmune rabbit IgG was used a negative control. Nuclear and cytoplasmic HSPH1/HSP105 immunostaining were observed in the luminal (Le) and glandular (G) epithelial cells, stromal fibroblast (f) and macrophages $(\mathrm{m})$ of endometrium and myometrial myocytes $(\mathrm{mmc})$. S: stroma, Sv: Stratum vasculare, v: blood vessel, black arrow heads: macrophages, black arrows: fibroblasts, thin black arrows: HSP105/110-negative region in the cytoplasm of myometrial smooth muscle cells, white arrows: lymphocytes, white arrow heads: HSP105/110-positive immunostaining in the lateral membrane of the luminal epithelial cells. Scale bars $=10 \mu \mathrm{m}$. 
Uterine stroma

During the entire postpartum involution period, the cytoplasm and nuclei of the stromal fibroblasts stained rather strongly (Fig. 5) and the macrophages (Fig. 5) and mast cells (Fig. 6) presented only moderate cytoplasmic immunostaining for HSPH1/HSP105.

\section{Myometrium}

On postpartum days 1 and 3 the myocytes of the inner and outer myometrium showed a weak nuclear and moderate cytoplasmic HSPH1/HSP105 immunoreaction, whereas on postpartum days 5 and 10 , this immunoreaction intensified in the cytoplasm and reached a strong intensity (Fig. 5).

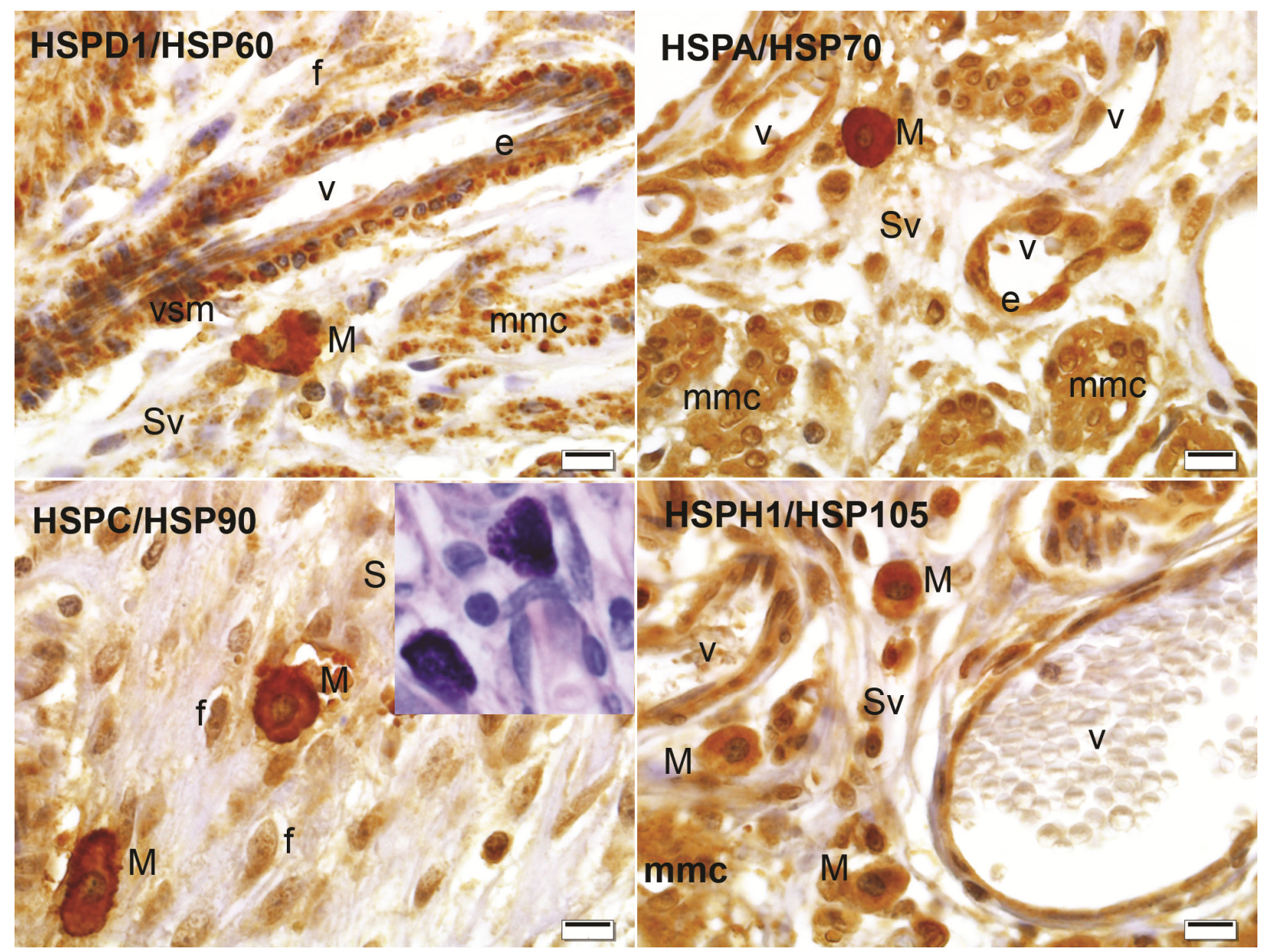

Figure 6. Representative samples showing cytoplasmic expressions of HSPD1/HSP60, HSPA/HSP70, HSPC7HSP90 and HSPH1/HSP105 in the uterine mast cells. Dominici staining made possible the identification of these as mast cells, as suspected by previous observations in sections stained with immunohistochemistry (inset pictures). Scale bars $=10 \mu \mathrm{m}$.

\section{Discussion}

The process of postpartum uterine involution is similar to that of the tissue repair in other organs (Salamonsen, 2003). Because the proliferation that occurs during the tissue repair process requires a higher rate of protein synthesis and the protein folding quality control does not occur randomly in cells, but requires the action of specialized molecular chaperones such as heat shock proteins (HSPs) compartmentalized in subcellular microenvironments and organelles (Pechan, 1991). The major role of HSPs is to prevent protein misfolding and aggregation both under normal conditions and when cells are exposed to stress (Hendrick and Hartl, 1993). Therefore, determining the sub-cellular localization of a heat shock protein within a cell is often an essential step towards understanding its function. In the present study study, the cellular and subcellular localization of HSPs (HSPD1/HSP60, HSPA/HSP70, HSPC/HSP90 and HSPH1/HSP105) in the endometrial and myometrial components of the rat uterus throughout the physiological involution process was analysed by immunohistochemistry.

In this study, the specificity of the immunohistochemical procedures and the cellular localization of HSPs were checked using positive control tissues such as human colon and breast carcinoma. In this positive control tissues, HSPD1/HSP60 immunostaining was localized to the cell cytoplasm and was characterized by a punctategranular pattern, whereas specific immunoreactivities for HSPA/HSP70, HSPC/HSP90 and HSPH1/HSP105 
were observed in the nucleus and cytoplasm of carcinoma cells. These data were in agreement with the immunohistochemical results obtained with colon and breast carcinoma cells as described in previous studies (Shah et al., 1998; Yano et al., 1996; Romanucci et al., 2008). Similarly, in all cells of the involuting uterus, HSPD1/HSP60 immunostaining was present in the cytoplasm, often with a granular appearance, whereas HSPA/HSP70, HSPC/HSP90, and HSPH1/HSP105 immunostainings were localized in the nucleus (nuclear membrane) and cytoplasm. Furthermore, HSPH1/HSP105 immunoreactivity was also observed in the lateral membrane of the luminal epithelium on postpartum day 10, thus indicating the presence of membrane-bound HSPH1/HSP105.

HSPD1/HSP60 mostly localized in the mitochondrial matrix, but localization in other cellular subcompartments have been reported (Soltys and Gupta, 1996; 1997; Gupta and Knowlton, 2002; Cappello et al., 2008). In the present study, the subcellular localization of HSPD1/HSP60 was not examined by electron microscopy. However, the observation of the granular pattern of HSPD1/HSP60 immunoreactivity throughout the cytoplasm of uterine cells in the rat may indicate that HSPD1/HSP60 is located in the mitochondria and other cytoplasmic organelles.

Since it is known that HSPA/HSP70 is expressed in the cytoplasm of mammalian cells in normal conditions and transported into the nucleus after the stress (Song et al., 2015), the presence of cytoplasmic and nuclear localization of HSPA/HSP70 in the rat uterine cells may supports the opinion that involution process creates a stressful microenvironment for the uterine cells and induces the nuclear localization of HSPA/HSP70 for cell survival after stress.

HSPC/HSP90 is constantly present at low level in normal tissues and is necessary for the early $\mathrm{S}$ phase of the cell cycle (Milarski and Morimoto, 1986; Jerome et al., 1993). Furthermore, HSPC/HSP90 is localized predominantly in the cytoplasm, but with different amounts in the nucleus (Sreedhar et al., 2004). The present study was performed using an antiHSP $90 \alpha / \beta$ polyclonal antibody to HSPC $1 / \mathrm{HSP} 90 \alpha$ and HSPC $3 /$ HSP90 $\beta$ to determine their presence and cellular localization in the involuting rat uterus. In this study, an association of the HSPC1/HSP90 $\alpha$ and HSPC3/HSP90 $\beta$ with the nuclear membrane and cytoplasm was clearly observed. Thus, the cytoplasmic immunolocalization of HSPC/HSP90 isoforms in the involuting uterus suggests that HSPC1/HSP90 $\alpha$ and HSPC3/HSP90 $\beta$ may be involved in many physiological processes, such as cell cycle control, cell proliferation, regulation of cell death and survival, and differentiation during the involution process as reported in previous studies (Milarski and Morimoto, 1986; Jerome et al., 1993; Sreedhar et al., 2004). Furthermore, localization of HSPC/HSP90 in the nuclear membrane during the involution process may be related to the ability of HSPC/HSP90 to maintain the integrity of the nuclear envelope as suggested by Langer et al. (2003).

Previous reports have shown that HSPH1/HSP105 is localized to the cytoplasm and nucleus of mammalian cells under both non-stressed and stressed conditions (Yasuda et al., 1995; Saito et al., 2007; 2009). Consistent with these reports (Yasuda et al., 1995; Saito et al., 2007; 2009), the nuclear and cytoplasmic localization of HSPH1/HSP105 protein was observed in the cells of involuting uterus.

It is known that HSPs have different functions, depending on their intracellular or extracellular location. Although extracellular or membrane-bound HSPs mediate immunological functions, intracellular HSPs have mainly a cytoprotective/antiapoptotic function (Lanneau et al., 2007; Schmitt et al., 2007). Although HSPD1/HSP60 appears to have both pro-survival and pro-death functions (Chandra et al., 2007), both HSPA/HSP70 and HSPC/HSP90 are anti-apoptotic HSPs, and their overexpression allows cells to survive in various conditions (Jolly and Morimoto, 2000; Garrido et al., 2001; Parcellier et al., 2003). However, HSPH1/HSP105 may function as a pro-apoptotic factor (Yamagishi et al., 2002) or as an anti-apoptotic factor in mammals, depending on the cell types (Hatayama et al., 2001). Nevertheless, the immunohistochemical data of present study could not determine the exact role of HSPA/HSP70, HSPC/HSP90 and HSPH1/HSP105 in the uterine cells during involution process. However, based on information in the literature (Jolly and Morimoto, 2000; Garrido et al., 2001; Parcellier et al., 2003; Yamagishi et al., 2002; Hatayama et al., 2001), it may be suggested that these intracellular HSPs may function as cytoprotective/anti-apoptotic factors and their expression allows uterine cells to survive in the physiological involution conditions. Additionally, it may be suggested that the nuclear reactivity could also mediate a protective function for the uterine cells, as the nuclear localization of HSPs is associated with cell stress and cell growth (Knowlton and Salfity, 1996).

Several reports have shown that the expressions and localizations of HSPs in the endometrium are different from each other and vary in accordance with the menstrual or oestrous cycle and pregnancy (Nip et al., 1994; Koshiyama et al., 1995; Tang et al., 1995; Tabibzadeh et al., 1996; Shah et al., 1998; Tabibzadeh and Broome, 1999; Lachance et al., 2007; Yuan et al., 2009; Chae et al., 2011; Jaiswal et al., 2013). Previous studies of human endometrium (Nip et al., 1994; Koshiyama et al., 1995; Tabibzadeh et al., 1996; Tabibzadeh and Broome, 1999) have reported that the expression of the HSPC/HSP90 protein showed minimal changes throughout the menstrual cycle and the expression of HSPD1/HSP60 increased progressively during the late proliferative/early secretory phases, whereas the inducible form of HSPA/HSP70 did not undergo these changes. However, the study by Tabibzadeh et al. (1996) reported that the immunohistochemical staining failed to reveal significant changes in the immunoreactivity of HSPD1/HSP60, HSPA/HSP70 and HSPC/HSP90 throughout the menstrual cycle. Furthermore, in a previous study of rat uterus, Yuan et al. (2009) reported that the highest expression of HSPH1/HSP105 was observed on day 5 and day 6 , around the time before and after implantation. In the present study, a 
semiquantitative scoring method was used to assess HSP immunostaining in the endometrial and myometrial compartments of the involuting uterus. Therefore, the expression levels of HSPs in the rat uterus during the postpartum involution period were not determined quantitatively. However, the semiquantitative data gathered in this study clearly revealed that expression levels and patterns of all examined proteins varied with the structural changes in the endometrium and myometrium during the involution period.

Some earlier studies have shown that immunoreactivity for HSPD1/HSP60 and HSPC/HSP90 is observed in both the epithelium and stroma of the human endometrium (Koshiyama et al., 1995; Tabibzadeh et al., 1996), whereas HSPA/HSP70 is primarly expressed in the epithelial cells. Moreover, with the exception of a decrease in the intensity of HSPD1/HSP60 staining in the endometrial glands during the menstrual phase, there were no detectable changes in the immunoreactivity of HSPD1/HSP60, HSPA/HSP70 and HSPC/HSP90 during the menstrual cycle. However, Lachance et al. (2007) reported that HSPD1/HSP60 was expressed by luminal and glandular epithelial cells, but not stromal cells. One study examining HSPH1/HSP105 expression in the rat uterus during early pregnancy showed the time-dependent expression of HSPH1/HSP105 in the luminal, glandular epithelium and stromal cells of the endometrium (Yuan et al., 2009). The immunohistochemical data of present study showed that HSPD1/HSP60, HSPA/HSP70, HSPC/HSP90 and HSPH1/HSP105 were expressed in the cells of luminal and glandular epithelia and stroma in the endometrium of the rat uterus during the postpartum involution period and the nuclear and cytoplasmic immunostaining intensities of all HSPs changed in the luminal epithelium during the postpartum period but remained relatively stable in the other endometrial components. For example, on postpartum day 3, although the luminal epithelium presented weak immunoreactivity localized to the apical part of cells due to the decreased cellular height of the luminal epithelium, the crypt and glandular epithelia produced strong immunostaining for all HSPs. Following day 5 after parturition, the immunoreactions in the luminal epithelium were more intense than the glandular epithelium because the epithelial cells lining the lumen were columnar and the vacuolization in the epithelium disappeared. In addition, in agreement with some findings from Tabibzadeh et al. (1996), who reported that the nuclear staining for HSPC/HSP90 in the endometrial epithelium was more pronounced than the cytoplasmic staining during the entire menstrual cycle, the nuclear staining for HSPC/HSP90 in the luminal epithelium displayed the typical "homogeneous" pattern of nuclear staining, was more intense than the cytoplasmic staining, and was stronger on postpartum day 10 compared with the other days. These findings revealed that the expression patterns of HSPs in the epithelium varied with the morphological changes that occurred during the involution process.

Early studies conducted in the uterus showed that the expression levels of HSPs in the endometrial stromal cells differ from each other and vary according to the menstrual cycle (Tabibzadeh et al., 1996; Komatsu et al., 1997) and pregnancy (Yuan et al., 2009). Although Lachance et al. (2007) reported that the stromal cells in the human uterus exhibited weak immunostaining for HSPD1/HSP60 and Komatsu et al. (1997) showed that the stromal cells in the functionalis layer of the human uterus were negative or very weakly positive for HSPA/HSP70 during both the proliferative and secretory phases, the findings of present study corroborate the expression of HSPD1/HSP60 and HSPA/HSP70 in stromal cells, including fibroblasts, endothelial cells in newly forming vessels, macrophages and neutrophils, in the rat uterus throughout the involution period. Furthermore, Komatsu et al. (1997) determined that the stromal cells in the human uterus are positive for HSPC/HSP90 throughout the menstrual cycle. Moreover, reports from other authors (Yuan et al., 2009) indicated that HSPH1/HSP105 staining is observed in the stromal cells immediately underneath the luminal epithelium in the rat uterus on day 4 and day 5 of pregnancy. In agreement with these reports (Komatsu et al., 1997; Yuan et al., 2009), HSPC/HSP90 and HSPH1/HSP105 immunoreactivities were observed in fibroblasts of rat uterus throughout the involution period. This study also indicate that the number of immunopositive fibroblasts for each HSP increased with the advancement of postpartum days and reached a maximum on postpartum day 10 .

Although, HSPC/HSP90 and HSPH1/HSP105 have been reported to be expressed in the endometrial stromal cells, the precise functions of HSPC/HSP90 and HSPH1/HSP105 in endometrial fibroblasts are unknown. However, several studies have shown that the elevated expression of HSPA/HSP70 and HSPC/HSP90 in dermal fibroblasts enhanced cell survival following heat shock (Liu et al., 1992), and HSPC/HSP90 facilitates the migration of dermal fibroblasts and the maturation of the ECM, which are required for wound healing ( $\mathrm{Li}$ et al., 2007). Given the role of HSPA/HSP70, HSPC/HSP90 and HSPH1/HSP105 in various cellular processes, such as controlling cell proliferation, survival, differentiation and apoptosis (Milarski and Morimoto, 1986; Sreedhar et al., 2004; Yuan et al., 2009) and the literature reports cited above (Liu et al., 1992; Li et al., 2007), it may be suggested that the expression of HSPA/HSP70, HSPC/HSP90 and HSPH1/HSP 105 in the endometrial fibroblasts could be associated with the survival and mobility of these cells during the involution process.

It has been reported that monocytes and macrophages express several members of HSP family such as HSPD1/HSP60, HSPA/HSP70 and HSPC/HSP90 (Twomey et al., 1993; Sondermann et al., 2000; Oehler et al. 2001; Habich et al., 2002; Jin et al., 2002; Liang et al. 2007; Fagone et al., 2012) and HSPs play essential roles in antigen presentation and activation of macrophages (reviewed in Tsan and Gao 2009). The present study corroborates the localization of HSPD1/HSP60, HSPA/HSP70, HSPC/HSP90 and HSPH1/HSP105 in uterine macrophages, and the HSP expression occurs in an involution-dependent manner, because the number of 
HSP-positive endometrial macrophages increased with the advancement of postpartum days.

In the literature, there were few reports on the expression of HSPs in mast cells (MCs) (Cohen-Saidon et al., 2006; Shabelnikov et al., 2012), and no information was reported regarding the expression of HSPs in the uterine MCs. Consequently the expression and functions of HSPs in uterine mast cells are unknown. Shabelnikov et al. (2012) have shown that HSPA/HSP70 immunoreactivity was present in situ in granules of mucosal and connective tissue MCs of rats that were not subjected to stress, but it was not expressed in MCs that were activated by stress factors. CohenSaidon et al. (2006) reported that the antiapoptotic function of Bcl-2 in MCs is dependent on its association with HSPC3/HSP90 $\beta$. In agreement with the report from Shabelnikov et al. (2012) on rat mast cells, the present study indicates that the mast cells exhibited HSPD1/HSP60, HSPA/HSP70, HSPC/HSP90 and HSPH1/HSP105 positive cytoplasmic immunolabelling.

To the best of author knowledge, there is only one study illustrating the expression of HSPs in the myometrium. Komatsu et al. (1997) reported that although immunoreactivity for HSPA/HSP70 and HSPC/HSP90 was observed in myometrial myocytes in the human uterus throughout the menstrual cycle, the HSPA/HSP70 and HSPC/HSP90 mRNA and protein levels in the myometrium were significantly higher in the proliferative phase compared to those in the secretory phase. The current study showed marked expression of HSPD1/HSP60, HSPA/HSP70, HSPC/HSP90 and HSPH1/HSP105 in the myometrium of involuting uterus. However, it was detected that the intensities of HSPD1/HSP60, HSPA/HSP70, HSPC/HSP90 immunostaining in the myometrium did not influence by postpartum involution day, except for HSPH1/HSP105.

In conclusion, the results indicate that HSPD1/HSP60, HSPA/HSP70, HSPC/HSP90 and HSPH1/HSP105 in the uterus are expressed in a temporal and cell-specific manner and the localization patterns of these HSPs are influenced by morphological changes during the postpartum involution period. These data support the hypothesis that the uterine involution conditions may generate a stressful environment for the uterine cells and induce the expression of HSPs, and thus HSPs produced by uterine cells are involved in the remodelling and regeneration of the endometrium and the reduction in the size of the myometrial cells during the involution process. However, further investigations are still required to clarify the function of HSPs at both the cellular and molecular level in the involuting uterus.

\section{Acknowledgments}

This study was financially supported by Scientific Research Council of Erciyes University (Project No: TSY-10-3052).

\section{References}

Alan E, Liman N, Sağsöz H. 2015. The profile of the epidermal growth factor system in rat endometrium during postpartum involution period. Vet Res Commun, 39:115-135.

Atalay M, Oksala N, Lappalainen J, Laaksonen DE, Sen CK, Roy S. 2009. Heat shock proteins in diabetes and wound healing. Curr Protein Pept Sci, 10:85-95.

Cappello, F, Conway de Macario E, Marasà L, Zummo G, Macario AJL. 2008. Hsp60 expression, new locations, functions, and perspectives for cancer diagnosis and therapy. Cancer Biol Ther, 7:801-809.

Chae J-Il, Kim J, Lee SG, Jeon Y-J, Kim D-W, Soh Y, Seo KS, Lee HK, Choi N-J, Ryu J, Kang S, Cho SK, Lee D-S, Chung HM, Koo D-B. 2011. Proteomic analysis of pregnancy-related proteins from pig uterus endometrium during pregnancy. Proteome Sci, 9:41. doi: 10.1186/1477-5956-9-41.

Chandra D, Choy G, Tang DG. 2007. Cytosolic accumulation of HSP60 during apoptosis with or without apparent mitochondrial release: evidence that its pro-apoptotic or pro-survival functions involve differential interactions with caspase-3. J Biol Chem, 282:31289-31301.

Ciocca DR, Stati AO, Fanelli MA, Gaestel M. 1996. Expression of heat shock protein 25,000 in rat uterus during pregnancy and pseudopregnancy. Biol Reprod, 54:1326-1335.

Cohen-Saidon C, Carmi I, Keren A, Razin E. 2006. Antiapoptotic function of $\mathrm{Bcl}-2$ in mast cells is dependent on its association with heat shock protein 90ß. Blood, 107:1413-1420.

Craig EA, Weissman JS, Horwich AL. 1994. Heat shock proteins and molecular chaperones: mediators of protein conformation and turnover in the cell. Cell, 78:365-372.

Crossmon GA. 1937. Modification of Mallory's connective tissue stain with a discussion of the principles involved. Anat Rec, 69:33-38.

Detre S, Saclani JG, Dowsett M. 1995. A “quickscore" method for immunohistochemical semiquantitation: validation for oestrogen receptor in breast carcinomas. $J$ Clin Pathol, 48:876-878.

Fagone P, Di Rosa M, Palumbo M, De Gregorio C, Nicoletti F, Malaguarnera L. 2012. Modulation of heat shock proteins during macrophage differentiation. Inflamm Res, 61:1131-1139.

Galea-Lauri J, Latchman DS, Katz DR. 1996. The role of the $90-\mathrm{kDa}$ heat shock protein in cell cycle control and differentiation of the monoblastoid cell line U937. Exp Cell Res, 226: 243-254.

Garrido C, Gurbuxani S, Ravagnan L, Kroemer G. 2001. Heat shock proteins: endogenous modulators of apoptotic cell death. Biochem Biophys Res Commun, 286:433-442.

Grigore M, Indrei A. 2001. The role of heat shock proteins in reproduction. Rev Med Chir Soc Med Nat Iasi, 105:674-676.

Gu H-N, Cheong H-T, Yang B-K, Park C-K. 2012. Relationship between plasminogen activator (PA) and HSP-90 in uterus tissue during the porcine estrous cycle. Reprod Dev Biol, 36:219-223.

Gupta S, Knowlton AA. 2002. Cytosolic HSP60, hypoxia and apoptosis. Circulation, 106:2727-2733.

Habich C, Baumgart K, Kol, H, Burkart V. 2002. 
The receptor for heat shock protein 60 on macrophages is saturable, specic, and distinct from receptors for other heat shock proteins. J Immunol, 168:569-576.

Hamid HY, Zakaria, MZAB. 2013. Reproductive characteristics of the female laboratory rat. $A f r J$ Biotechnol, 12:2510-2514.

Hatayama T, Yamagishi N, Minobe E, Sakai K. 2001. Role of HSP105/110 in protection against stressinduced apoptosis in neuronal PC12 cells. Biochem Biophys Res Commun, 288:528-534.

Hendrick JP, Hartl FU. 1993. Molecular chaperone functions of heat-shock proteins. Annu Rev Biochem, 62:349-384

Jaiswal MK, Agrawal V, Jaiswal YK. 2013 Lipopolysaccharide drives alternation of heat shock proteins and induces failure of blastocyst implantation in mouse. Biol Reprod, 88:1-12.

Jerome V, Vourch C, Baulieu EE, Catelli MG. 1993. Cell cycle regulation of the chicken hsp90 $\alpha$ expression. Exp Cell Res, 205:44-51.

Jin HS, Yoshino T, Jin Z, Oka T, Kobayashi K, Yamasaki R, Liu YX, Yokota K, Ogumo K, Agaki T. 2002. Expression of heat shock protein 60 in normal and neoplastic human lymphoid tissues. $J$ Clin Exp Hematopathol, 42:25-32.

Jolly C, Morimoto RI. 2000. Role of the heat shock response and molecular chaperones in oncogenesis and cell death. J Natl Cancer Inst, 92:1564-1572.

Kampinga HH, Hageman J, Vos MJ, Kubota H, Tanguay RM, Bruforf EA, Cheetham ME, Chen B, Hightower LE. 2009. Guidelines for the nomenclature of the human heat shock proteins. Cell Stress Chaperon, 14:105-111.

Knowlton AA, Brecher P, Apstein CS. 1991. Rapid expression of heat shock protein in the rabbit after brief cardiac ischemia. J Clin Invest, 87:139-147.

Knowlton AA, Salfity M. 1996. Nuclear localization and the heat shock proteins. J Biosci, 21:123-132.

Komatsu T, Konishi I, Fukumoto M, Nanbu K, Koshiyama M, Mandai M, Mori T. 1997. Messenger ribonucleic acid expression of heat shock proteins HSP70 and HSP90 in human endometrium and myometrium during the menstrual cycle. $J$ Clin Endocrinol Metab, 82:1385-1389.

Koshiyama M, Konishi I, Nanbu K, Nanbu Y, Mandai M, Komatsu T, Yamamoto S, Mori T, Fujii S. 1995. Immunohistochemical localization of heat shock proteins HSP70 and HSP90 in the human endometrium: correlation with sex steroid receptors and Ki-67 antigen expression. J Clin Endocrinol Metab, 80:1106-1112.

Lachance C, Bailey JL, Leclerc P. 2007. Expression of Hsp60 and Grp78 in the human endometrium and oviduct:and their effect on sperm functions. Hum Reprod, 22:2606-2614.

Langer T, Rosmus S, Fasold H. 2003. Intracellular localization of the $90 \mathrm{kDA}$ heat shock protein HSP90 $\alpha$. determined by expression of a EGFP-HSP90 $\alpha$-fusion protein in unstressed and heat stressed 3T3 cells. Cell Biol Int, 27:47-52.

Lanneau D, de Thonel A, Maurel S, Didelot C, Garrido C. 2007. Apoptosis versus cell differentiation.
Role of heat shock proteins HSP90, HSP70 and HSP27. Prion, 1:53-60.

Li, Y, Zhou X, Wei QW, Huang RH, Shi FX. 2014. Cell-specific expression and immunolocalization of nitric oxide synthase isoforms and soluble guanylyl cyclase and subunits in postnatal porcine uteri. Acta Histochem, 116:466-473.

Li W, Li Y, Guan S, Fan J, Cheng C-F, Bright AM, Chinn C, Chen M, Woodley DT. 2007. Extracellular heat shock protein-90 $\alpha$ : Linking hypoxia to skin cell motility and wound healing. EMBO J, 26:1221-1233.

Liang S-M, Kuo C-C, Liang C-M, Lai C-Y, Liang SM. 2007. Involvement of heat shock protein Hsp90 $\beta$ but not Hsp90 in antiapoptotic effect of CpG-B oligodeoxynucleotide. J Immunol, 178:6100-6108.

Liman N, Alan E, Küçük Bayram G, Gürbulak K. 2013. Expression of survivin, Bcl-2 and bax proteins in the domestic Cat Felis catus. endometrium during the oestrus cycle. Reprod Domest Anim, 48:33-45.

Liu RY, Li X, Li L, Li GC. 1992. Expression of human hsp70 in rat fibroblasts enhances cell survival and facilitates recovery from translational and transcriptional inhibition following heat shock. Cancer Res, 52:3667-3673.

Milarski KL, Morimoto RI. 1986. Expression of human HSP70 during the synthetic phase of the cell cycle. Proc Natl Acad Sci USA, 83:9517-9521.

Neuer A, Ruck P, Marzusch K, Dietl J, Kaiserling E, Horny HP, Witkin SS. 1996. Human heat shock proteins in first trimester human decidua. Infect Dis Obstet Gynecol, 3:188-189.

Neuer A, Spandorfer SD, Giraldo P, Dieterle S, Rosenwaks Z, Witkin SS. 2000. The role of heat shock proteins in reproduction. Hum Reprod Update, 6:149159.

Nip M, Miller D, Taylor P, Gannon M, Hancock K. 1994. Expression of heat shock protein $70 \mathrm{kDa}$ in human endometrium of normal and infertile women. Hum Reprod, 9:1253-1256.

Nollen EA, Morimoto RI. 2002. Chaperoning signaling pathways: molecular chaperones as stresssensing 'heat shock' proteins. J Cell Sci, 115:2809-2816. Oehler R, Pusch E, Zellner M, Dungel P, Hergovics N, Eliasen MM, Brabec M, Roth E. 2001. Cell typespecific variations in the induction of hsp70 in human leukocytes by feverlike whole body hyperthermia. Cell Stress Chaperon, 6:306-315.

Papaconstantinou AD, Goering PL, Umbreit TH, Brown KM. 2003. Regulation of uterine hsp90alpha, hsp72 and HSF-1 transcription in B6C3F1 mice by betaestradiol and bisphenol A: involvement of the estrogen receptor and protein kinase C. Toxicol Lett, 144:257270.

Parcellier A, Gurbuxani S, Schmitt E, Solary E, Garrido C. 2003. Heat shock proteins, cellular chaperones that modulate mitochondrial cell death pathways. Biochem Biophys Res Commun, 304:505-512. Pechan PM. 1991. Heat shock proteins and cell proliferation. FEBS Lett, 280:1-4.

Picard D. 1998. The role of heat shock proteins in the regulation of steroid receptor function. In: Freedman LP Ed. The molecular biology of steroid and nuclear 
hormone receptors. Birkhaüser, Boston, pp1-18.

Pratt WB, Welsh MJ. 1994. Chaperone functions of the heat shock proteins associated with steroid receptors. Cell Biol, 5:83-93.

Ramachandran C, Catelli MG, Schneider W, Shyamala G. 1988. Estrogenic regulation of uterine 90kilodalton heat shock protein. Endocrinol, 123:956-961.

Romanucci M, Bastow T, Salda LD. 2008. Heat shock proteins in animal neoplasms and human tumours-a comparison. Cell Stress Chaperon, 13:253-262.

Salamonsen LA. 2003. Tissue injury and repair in the female human reproductive tract. Reproduction, 125:301-311.

Saito Y, Yamagishi N, Hatayama T. 2007. Different localization of HSP $105 / 110$ family proteins in mammalian cells. Exp Cell Res, 313:3707-3717.

Saito Y, Yamagishi N, Hatayama T. 2009. Nuclear localization mechanism of HSP105/110beta and its possible function in mammalian cells. $J$ Biochem, 145:185-191.

Schmitt E, Gehrmann M, Brunet M, Multhoff G, Garrido C. 2007. Intracellular and extracellular functions of heat shock proteins: repercussions in cancer therapy. J Leukoc Biol, 81:15-27.

Shabelnikov SV, Bystrova OA, Martynova MG 2012. Localization of heat shock protein 70 in rat mast cells. Cell Tissue Biol, 6:228-232.

Shah M, Stanek J, Handwerger S. 1998. Differential localization of heat shock proteins $90,70,60$ and 27 in human decidua and placenta during pregnancy. Histochem J, 30:509-518.

Soltys BJ, Gupta RS. 1996. Immunoelectron microscopic localization of the $60-\mathrm{kDa}$ heat shock chaperonin protein HSP60. in mammalian cells. Exp Cell Res, 22:16-27.

Soltys BJ, Gupta RS. 1997. Cell surface localization of the $60 \mathrm{kDa}$ heat shock chaperonin protein HSP60. in mammalian cells. Cell Biol Int, 21:315-320.

Sreedhar AS, Kalmar E, Csermely P, Shen YF. 2004. Hsp90 isoforms: functions, expression and clinical importance. FEBS Lett, 562:11-15.

Sondermann H, Becker T, Mayhew M, Wieland F, Hartl FU. 2000. Characterization of a receptor for heat shock protein 70 on macrophages and monocytes. Biol Chem, 381:1165-1174.

Song J, Hong H, Ko J, Park E-J, Park SM, Son S-Y, Lee SJ. 2015. Structure and nuclear transport mechanism of HSP70 nuclear transporter, Hikeshi.
Biodesign, 3:117-122.

Sotiriou S, Liatsos K, Ladopoulos I, Arvanitis DL. 2004. A comparison in concentration of heat shock proteins (HSP) 70 and 90 on chorionic villi of human placenta in normal pregnancies and in missed miscarriages. Clin Exp Obstet Gynecol, 31:185-190.

Stetler RA, Gan Y, Zhang W, Liou AK, Gao Y, Cao G, Chen J. 2010. Heat shock proteins: Cellular and molecular mechanisms in the CNS. Prog Neurobiol, 92:184-221.

Tabibzadeh S, Kong QF, Satyaswaroop PG, Babaknia A. 1996. Heat shock proteins in human endometrium throughout the menstrual cycle. Hum Reprod, 11:633-640.

Tabibzadeh S, Broome J. 1999. Heat shock proteins in human endometrium throughout the menstrual cycle. Infect Dis Obstet Gynecol, 7:5-9.

Tang PZ, Gannon MJ, Andrew A, Miller D. 1995. Evidence for oestrogenic regulation of heat shock protein expression in human endometrium and steroidresponsive cell lines. Eur J Endocrinol, 133:598-605.

Tsan MF, Gao B. 2009. Heat shock proteins and immune system. J Leukoc Biol, 85:905-910.

Twomey BM, McCallum S, Isenberg DA, Latchman DS. 1993. Elevation of heat shock protein synthesis and hsp gene transcription during monocyte to macrophage differentiation of U937 cells. Clin Exp Immunol, 93:178-183.

Yamagishi N, Ishihara $K$, Saito $Y$, Hatayama $T$. 2002. HSP105/110alpha enhances stress-induced apoptosis but not necrosis in Mouse embryonal $\mathrm{f} 9$ cells. J Biochem, 132:271-278.

Yano M, Naito Z, Tanaka S, Asanao G. 1996. Expression and roles heat shock proteins in human breast cancer. Jpn J Cancer Res, 87: 908-915.

Yasuda K, Nakai A, Hatayama T, Nagata K. 1995. Cloning and expression of murine high molecular mass heat shock proteins, HSP105/110. J Biol Chem, 270:29718-29723.

Yuan JX, Xiao LJ, Zhang XS, Liu T, Chen M, Hu ZY, Gao F, Liu YX. 2009. Increased expression of heat shock protein 105 in rat uterus of early pregnancy and its significance in embryo implantation. Reprod Biol Endocrinol, 13:7-23.

Zigert M, Witkin SS, Sziller I, Alexander H, Brylla E, Härtig W. 1999. Heat shock proteins and heat shock protein-antibody complexes in placental tissues. Infect Dis Obstet Gynecol, 7:180-185. 